\title{
NOTAS SOBRE PRECINTOS Y PONDERALES. I. VARIOS PRECINTOS DE SULH A NOMBRE DE 'ABD ALLĀH IBN MĀLIK: CORRECCIONES Y UNA POSIBLE ATRIBUCIÓN. II. ADICIONES A «PONDERALES ANDALUSÍES»
}

En el presente escrito se añaden varias piezas hasta ahora inéditas tanto al corpus de precintos producidos durante el período inicial de al-Andalus, como al de los ponderales relacionados con las emisiones monetarias de épocas diversas en la historia andalusí.

Palabras clave: Precintos; sulh; 'Abd Allāh; Ibn Mālik; ponderales; dirham dajl arba 'in; dinar.
In this paper a number of items so far unregistered are added to both the catalogue of lead seals produced during the first period of Islamic Spain, and the catalogue of coin weights related to numismatic issues of different historical periods.

Keywords: Seals; Sulḥ; 'Abd Allāh; Ibn Mālik; Coin weights; Dirham dahl arba'ìn; Dinar.

\section{Varios precintos de șulh, a nombre de 'Abd Allāh ibn Mālik: correcciones y una posible atribución}

En el Congreso de Arqueología Medieval Española celebrado en Madrid en 1987 publicamos un corto artículo dedicado a precintos y amuletos de plomo procedentes de al-Andalus ${ }^{1}$. En el apartado sobre precintos dimos a conocer el muy modesto repertorio de dos tipos diferentes. Con relación a los mismos, mientras que la interpretación del n. ${ }^{\circ} 2$ de aquel trabajo no permite otra lectura, puesto que con la expresión ahl Iśbilliya, respaldada por el precedente egipcio ya publicado por Walker ${ }^{2}$, era evidentemente un precinto de yizya ${ }^{3}$, en lo que

1 Ibrahim, T., "Evidencia de precintos y amuletos en Al-Andalus", Congreso de Arqueología Medieval Española, Madrid, 1987, 705-710.

${ }^{2}$ Walker, J., A Catalogue of the Arab-Byzantine and Post-Reform Umaiyad Coins, Londres, 1956, 295.

${ }^{3}$ Desde entonces hemos podido tomar los datos e imagen de otros cinco precintos similares, cuatro de ellos con la misma expresión de ahl Išbilliya y uno de ahl Bâyah, que pensamos añadir a un trabajo en curso sobre precintos de primera época. En lo que se refiere a precintos de plomo de origen andalusí, que consideramos podrían ser en su mayo- 
respecta al $n^{\circ} 1$ - con el mismo número en el presente trabajo-, erramos de manera singular en relación con la función y lectura de parte de la leyenda de este precinto a nombre de 'Abd Allah ibn Mālik.

En concreto, en uno de los lados de dicho precinto leímos, dentro de recuadro rectangular y en dos líneas, bi-sm Allāh/țayyib ${ }^{4}$, «en el nombre de Dios/lícito», mientras que en su otro lado, con la misma disposición que el anterior, interpretamos, aunque con algunas dudas, el nombre 'Abd Allah/ibn Mãlik'.

Con la aparición de tres precintos más de ese tipo - recogidos aquí con los n.os 2, 3 y 4-, consideramos que la lectura correcta de la palabra anteriormente dada como tayyib sería sulh ${ }^{6}$, cuyo significado hablaría de «pacto»o «tratado», indicando un arreglo contractual pacífico, sulhan, en contraposición de lo que sería un acto de guerra: 'anwatan. Por tanto, la lectura completa del precinto sería, en una pri-

ría de la época de los Gobernadores, hemos recopilado información sobre más de 45 ejemplares que es posible agrupar en 17 tipos distintos, todos con epigrafía muy arcaica. Entre ellos, 12 se refieren a tributos de sulh y muestran el nombre de las siguientes localidades: Išbüliya, Šidūna, Ukšunūba (?) y Ŷayyān (?); sólo uno contiene la expresión fay' Allāh; unos cinco presentan la enigmática expresión de qism, y por último se han registrado cuatro con nombre propio, en concreto a nombre de al-Hurr. A los mencionados habría que añadir los cuatro del presente trabajo a nombre de 'Abd Allāh ibn Mãlik, además de los ya publicados de "Abd al-Rahmān ibn Mu'āwiya [Ibrahim, T., "Un precinto a nombre de "Abd al-Raḥmān I", Al-Qanțara XVI, 1 (1995), 143-146] y de 'Anbasa ibn Suhaym [Ibrahim, T., "Un precinto a nombre de "Anbasa ibn Suhaym al-Kalbī, gobernador de Al-Andalus, 103-107/721-725”, Al-Qanțara XX, 1 (1999), 191-193], sin olvidar la docena que muestran una lectura dificultosa que están demorando la publicación del conjunto.

${ }^{4}$ En el trabajo citado (Ibrahim, T., "Evidencia de precintos", 706-707, n. 1) se argumentó: "Si recordamos que en el cúfico arcaico normalmente se omite el alif de prolongación, se podría verosímilmente hacer otra lectura que sería Șālih o apto". Entonces no vimos que, de ser cierta esa observación, igualmente se hubiera omitido el alif de prolongación de Mālik.

5 La lectura del nombre ibn Mālik del precinto n. ${ }^{\circ} 1$ es bastante clara, diferenciándose el trazo final de la $d \bar{a} l$ de ' $A b d$, de la $k a \bar{f}$ al final de $M a \bar{a} l i k$, y lo mismo podría decirse de los n. ${ }^{\text {os }} 2,3$ y 4 . Es de notar que en el n. ${ }^{\circ} 1$ el círculo que parece estar encima de la $b \bar{a}^{\prime}$ de $i b n$ es una incrustación terrosa y no forma parte de la epigrafía

${ }^{6}$ La palabra es fácilmente apreciable en los precintos $\mathrm{n}^{\text {os }} 1,2$ y 3 -aunque en este último aparece algo dañado-, mientras que en el n. ${ }^{\circ} 4$ sólo se distingue su última letra. Cabría destacar que en este lado, en todos los ejemplos sin excepción, la epigrafía se presenta en un cúfico bien estructurado, al tiempo que el lado del nombre propio - a excepción del n. ${ }^{\circ} 1$ - la escritura es mucho menos formal y da muestras de apresuramiento o improvisación.

Al-Qanțara (AQ) XXVII 2, julio-diciembre 2006, pp. 329-335 ISSN 0211-3589 
mera cara y en dos líneas, Bi-sm Allāh/ṣulh, seguida, en la segunda cara, también en dos líneas, de 'Abd Allāh/ibn Mālik:

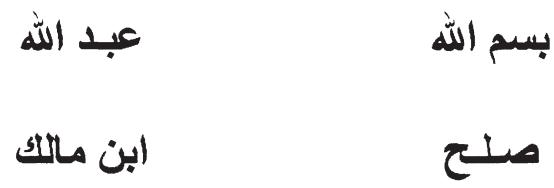

lo que podría ser traducido como: «En nombre de Dios, tratado de 'Abd Allāh ibn Mālik».

Los tratados de sulh no parecen haber sobrevivido, al menos con este término léxico, al período de los Gobernadores. Durante el mismo, el único Ibn Mālik conocido con ese nasab es al-Samh ibn Mālik (99-102 h.), nombrado directamente por 'Umar ibn 'Abd al- 'Azizz. Parece posible que el 'abd Allāh pudiera no ser un nombre propio sino más bien un apelativo de modestia en la forma de «siervo de Dios» ${ }^{7}$, postulación de humildad muy apropiada para un gobernador asignado por un personaje con la aureola de 'Umar ibn' Abd al-'Aziz.

\section{INVENTARIO}

Desde el punto de vista material, los cuatro precintos de plomo presentan un profundo surco en toda su circunferencia, que es donde se supone podría haber estado incrustado el alambre o similar materia de precintado. Los datos de los mismos son:

\footnotetext{
7 El uso de 'abd Allāh como apelativo de modestia en el sentido de "siervo de Dios" queda reflejado en la epigrafía de la época, aunque no sustituyendo al nombre, por ejemplo en la forma de 'Abd Allāh 'Abd al-Mālik amìr al-Mu'mininn' (Zain al-Din, N., Atlas of Arabic Calligraphy, Bagdad, 1968, 5, n. ${ }^{\circ}$ 7). Incluso se llega a usar esta forma en relación con el Profeta tal como es posible observar en las leyendas de los feluses del período: "Muhammad/'Abd Allāh/wa rasūlu-h" (Walker, J., A Catalogue, 219, n. ${ }^{\text {os }}$ 698-703). Es de notar el uso del alif en el ibn del nasab ibn Mālik que normalmente no hubiese sido necesario si el 'Abd Allāh hubiese sido ism.
}

Al-Qanțara (AQ) XXVII 2, julio-diciembre 2006, pp. 329-335 ISSN 0211-3589 


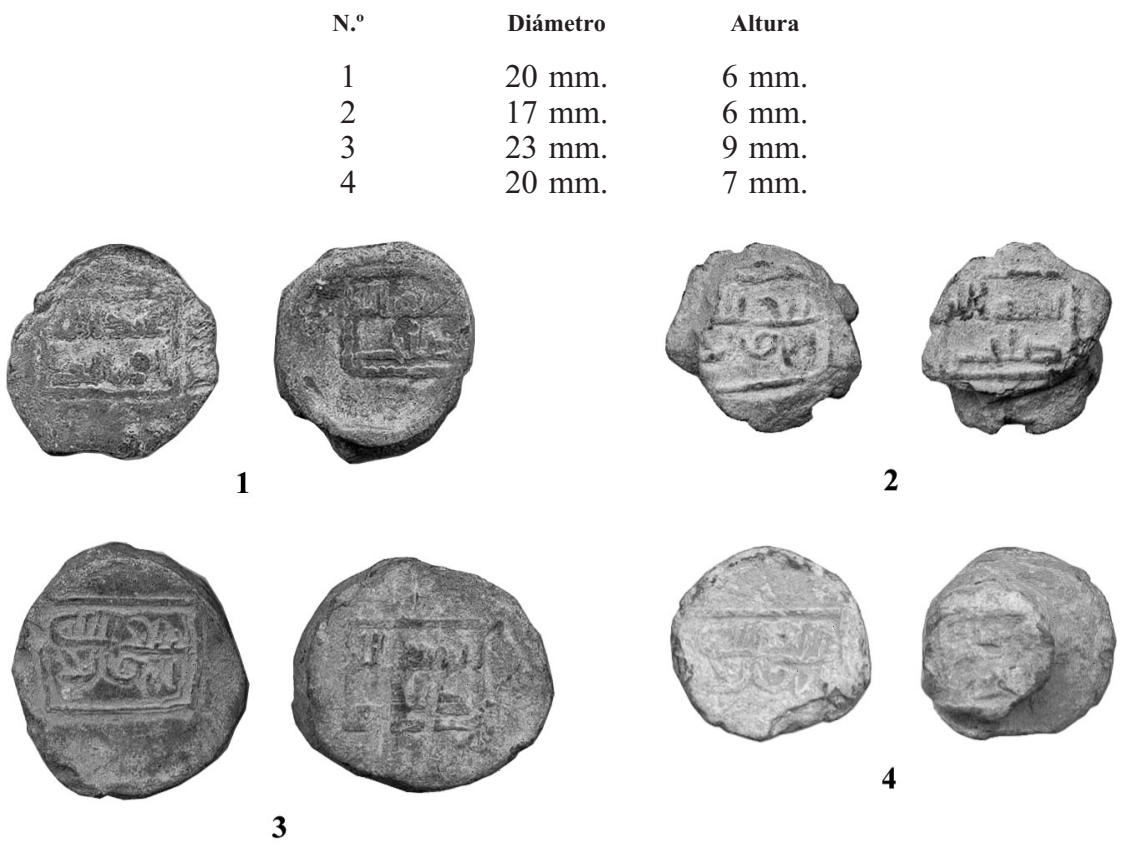

\section{Nota adicional a «Ponderales andalusíes»}

En la revista Numisma del año 1993, tras varios lustros de recopilar este tipo de material, fueron catalogados 71 ponderales andalut síes ${ }^{8}$. Ese trabajo fue completado un año después con la publicación de un anexo con el mismo título y en la misma revista, en el que se recogieron 21 ponderales más, junto a las láminas del anterior artículo, que habían sufrido el olvido del editor ${ }^{9}$.

Desde entonces hemos registrado bastantes ponderales más, que deberán necesariamente en un futuro sumarse a los ya publicados en forma de catálogo. En espera de que alguien, con más energía juvenil que el presente autor, se haga cargo de tal proyecto, nos ha parecido prudente, por si la espera se hace demasiado larga, adelantar en esta breve nota aquéllos que nos parecen más novedosos en lo que respecta a su contenido informativo.

8 Ibrahim, T., "Ponderales andalusíes", Numisma, 233 (1993), 39-68.

9 Ibrahim, T., "Ponderales andalusíes (Anexo)", Numisma, 234 (1994), 61-72. 


\section{CATÁlogo}

Ponderales de dirhams dajl arba'īn

A. De dos dírhams dajl arba iin.

Peso: 4,02 g. El peso de un solo dírham sería 4,01/2=2,01 g. Medidas: $11 \times 11 \mathrm{~mm}$.

Procedencia: provincia de Badajoz.

Leyendas:
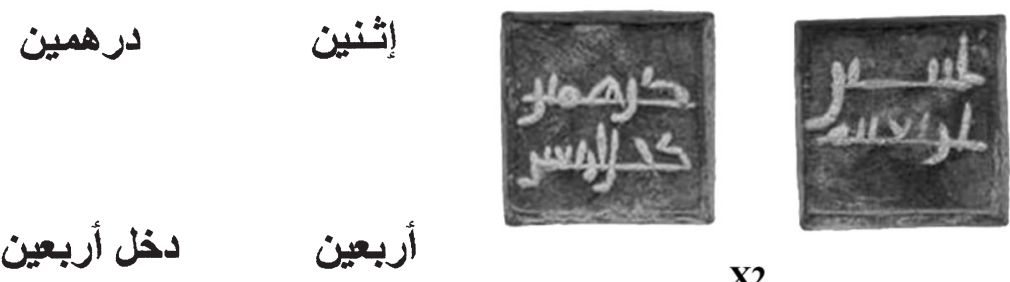

$\mathbf{X} 2$

B. De cuatro dírhams dajl arba 'in.

Peso: $8,10 \mathrm{~g}$. El peso de un solo dírham sería $8,10 / 4=2,025 \mathrm{~g}$. Medidas: $16 \times 16 \mathrm{~mm}$.

Procedencia: arrabales de Córdoba.

Leyendas: en un solo lado:
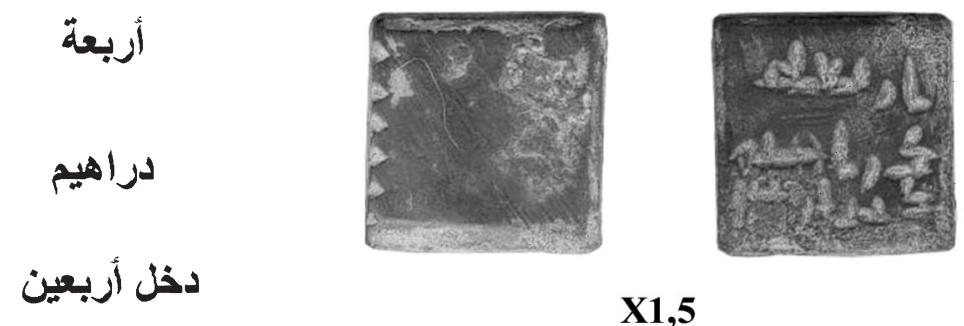

$\mathbf{X} 1,5$

Siguiendo lo expuesto sobre el dajl arba'in en el primero de los artículos citados ${ }^{10}$, creemos que estos ponderales son de cambio y lo que nos están proporcionando es el peso de plata relativamente pura,

10 Ibrahim, T., "Poderales andalusíes", 62-64.

Al-Qanțara (AQ) XXVII 2, julio-diciembre 2006, pp. 329-335 ISSN 0211-3589 
de dírham kayl o nuqra, como equivalente en valor al dírham califal, que, como ya ha quedado demostrado analíticamente, es de contenido sustancialmente inferior en plata a los que habían sido emitidos anteriormente ${ }^{11}$.

Ponderal con el nombre de al-Qādir bi-Allāh

C. Ũqiyya (¿?).

Peso: $24,80 \mathrm{~g}$.

Medidas: diámetro, $18 \mathrm{~mm}$; altura, $12 \mathrm{~mm}$.

Procedencia: provincia de Cuenca.

Leyendas:

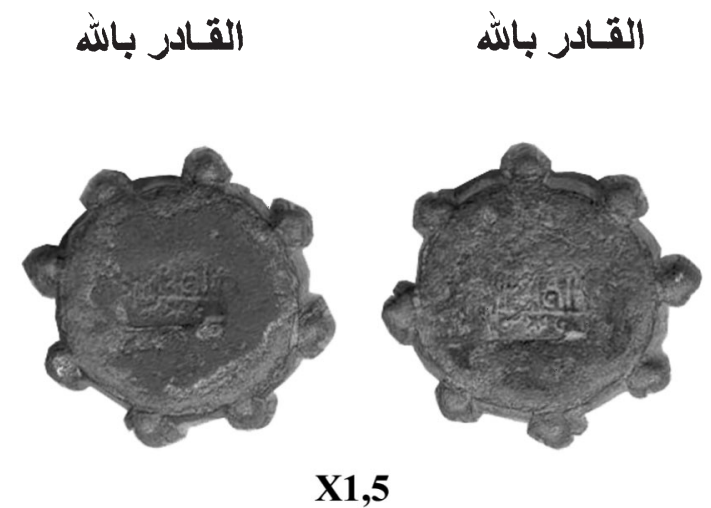

Este ponderal parece ser de la Taifa de Toledo bajo el mandato de al-Qādir bi-Allāh (467-483/1074-1090). Es de notar que la epigrafía, así como la estrella y el círculo decorativos, son muy similares - si no iguales- a los de ciertas monedas de este régulo ${ }^{12}$. Lo particular de este ponderal es que se trata del primero con nombre propio que es posible atribuir con cierta seguridad a un período y régulo concretos.

11 Canto, A. e Ibrahim, T., Moneda Andalusí: La colección del Museo Casa de la Moneda, Madrid, 2004, 48-50, 74, 76 y 78.

${ }_{12}$ Vives y Escudero, A., Monedas de las dinastías Arábigo-Españolas, Láminas, Madrid, 1998, n. ${ }^{\text {s }} 1127-1129$, lám. CX.

Al-Qanțara (AQ) XXVII 2, julio-diciembre 2006, pp. 329-335 ISSN 0211-3589 


\section{Ponderal de equivalencia a un dinar}

D. Ponderal equivalente al dinar.

Peso: $3,88 \mathrm{~g}$.

Medidas: diámetro, $13 \mathrm{~mm}$.

Leyendas, en un solo lado:
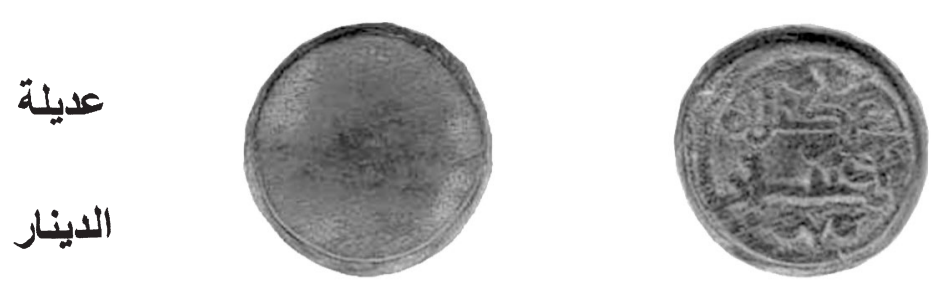

X2

Los ponderales ya catalogados que consideramos propiamente de dinar son relativamente abundantes ${ }^{13}$, pero en ninguno de ellos, a diferencia de los de $\operatorname{sarf}$ (cambio de oro a plata) ${ }^{14}$, viene explícitamente grabada la palabra «dinar», siendo este ponderal la singular excepción.

${ }^{13}$ Ibrahim, T., "Ponderales andalusíes", n. ${ }^{\text {os }} 16$-65, y "Ponderales andalusíes (Anexo)", n. ${ }^{\text {os }} 74-86$

${ }^{14}$ Ibrahim, T., "Ponderales andalusíes", n. ${ }^{\text {os }} 9-15$, y "Ponderales andalusíes (Anexo)", n. ${ }^{\text {os }} 72-73$.

Al-Qanțara (AQ) XXVII 2, julio-diciembre 2006, pp. 329-335 ISSN 0211-3589 